\title{
The risk of smoking on multiple sclerosis: a meta-analysis based on 20,626 cases from case-control and cohort studies
}

Peng Zhang, Rui Wang, Zhijun Li, Yuhan Wang, Chunshi Gao, Xin Lv, Yuanyuan Song, Bo Li

Background. Multiple sclerosis (MS) has become a disease that represents a tremendous burden on patients, families, and societies. The exact etiology of MS is still unclear, but it is believed that a combination of genetic and environmental factors contribute to this disease. Although some meta-analyses on the association between smoking and MS have been previously published, a number of new studies with larger population data have published since then. Consequently, these additional critical articles need to be taken into consideration. Method. We reviewed articles by searching in PubMed and EMBASE. Both conservative and non-conservative models were used to investigate the association between smoking and the susceptibility to MS. We also explored the effect of smoking on the susceptibility to MS in strata of different genders and smoking habits. The association between passive smoking and MS was also explored. Results. The results of this study suggest that smoking is a risk factor for MS (conservative model: odds ratio (OR) 1.55, 95\% Cl: 1.48-1.62, $\mathrm{p}<0.001$; non-conservative model: 1.57, 95\% Cl: 1.50-1.64, $\mathrm{p}<0.001$ ). Smoking appears to increase the risk of MS more in men than in women and in current smokers more than in past smokers. People who exposed to passive smoking have higher risk of MS than those unexposed. Conclusion. This study demonstrated that exposure to smoking is an important risk factor for MS. People will benefit from smoking cessation, and policymakers should pay attention to the association between smoking and MS. 
1 The risk of smoking on multiple sclerosis: A meta-analysis based on 20,626 cases from case-control and cohort studies.

3

4 Peng Zhang ${ }^{1}$ Rui Wang ${ }^{1}$ Zhijun $\mathrm{Li}^{1}$ Yuhan Wang ${ }^{1}$ Chunshi Gao ${ }^{1}$ Xin $\mathrm{Lv}^{1}$ Yuanyuan Song ${ }^{1}$ Bo $\mathrm{Li}^{1}$

61 Department of Epidemiology and Biostatistics, Jilin University School of Public Health,

7 Changchun, Jilin, China

8

9 Corresponding author:

10 Bo Li

111163 Xinmin Street, Changchun, Jilin 130021, China

13 E-mail: li_bo@jlu.edu.cn 


\section{Abstract:}

23 Background. Multiple sclerosis (MS) has become a disease that represents a tremendous burden on patients, families, and societies. The exact etiology of MS is still unclear, but it is believed that a combination of genetic and environmental factors contribute to this disease. Although some meta-analyses on the association between smoking and MS have been previously published, a number of new studies with larger population data have published since then. Consequently, these additional critical articles need to be taken into consideration.

Method. We reviewed articles by searching in PubMed and EMBASE. Both conservative and non-conservative models were used to investigate the association between smoking and the susceptibility to MS. We also explored the effect of smoking on the susceptibility to MS in strata of different genders and smoking habits. The association between passive smoking and MS was 33 also explored.

Results. The results of this study suggest that smoking is a risk factor for MS (conservative model: odds ratio (OR) 1.55, 95\%CI: 1.48-1.62, p<0.001; non-conservative model: $1.57,95 \% \mathrm{CI}: 1.50$ 1.64, $\mathrm{p}<0.001)$. Smoking appears to increase the risk of MS more in men than in women and in current smokers more than in past smokers. People who exposed to passive smoking have higher risk of MS than those unexposed.

Conclusion. This study demonstrated that exposure to smoking is an important risk factor for MS. People will benefit from smoking cessation, and policymakers should pay attention to the association between smoking and MS. 


\section{Introduction:}

43 Multiple sclerosis (MS) is an inflammatory disease that occurs when the spinal cord and the

44 insulating covers of the nerve cells in the brain are damaged. This damage affects the nervous

45 system's ability to communicate, resulting in a number of physical and mental problems

46 (Compston \& Coles 2002; Compston \& Coles 2008). Evidence indicates that MS is an autoimmune

47 disease that directly affects the central nervous system (CNS) myelin or oligodendrocytes. A variety of neurological signs and symptoms are determined by the distribution of white matter

lesions in the nervous system that may occur in sudden attacks or build up over time (Compston

$50 \&$ Coles 2008).

In 2013, there were about 1.5 million people who suffered from MS around the world, with rates varying widely in different regions and populations (WHO 2013). 19,800 people died from

MS in 2013, a statistic that was up from 12,400 people in 1990 (Collaborators. 2015). The disease

usually occurs between the ages of 20 to 50, occupying the leading position of disability among

young adults. The risk of MS for females is two times as high as males (Milo \& Kahana 2010).

The cause of MS is still not clear, but through rigorous epidemiological investigation, genetic

variations, the Epstein-Barr virus infection, vitamin D nutrition and cigarette smoking have been

identified as likely causal factors for MS (Handel et al. 2010; Ramagopalan et al. 2009; Simon et

al. 2012).

A previous meta-analysis published in 2014 reported a pooled odds ratio (OR) of 1.51 (95\%CI: 1.38-1.65) for the association between smoking and MS susceptibility (O'Gorman \& 
63

64

smoking in the etiology of MS because the sample sizes were relatively small. Many recent studies have explored the association between smoking and MS either directly or indirectly. Therefore, we conducted this meta-analysis to investigate the association in a larger sample. Moreover, we aimed to detect the effect of smoking on the incidence of MS in strata of different genders and smoking habits.

\section{Materials and methods}

\section{Search strategy}

We identified published studies that explored the association between smoking and the risk of MS by searching the PubMed and EMBASE databases from January $1^{\text {st }}, 1980$ to March 31st, 2015. The following search terms were used: "multiple sclerosis", "case-control”, "cohort study", "birth cohort", "survival analysis", "cigarette smoking", "tobacco smoking" and "cigars". In addition, the reference list of retrieved papers was also reviewed to identify additional relevant studies.

\section{Selection criteria}

The eligible studies needed to meet the following criteria: (1) the study must be an original study, (2) the study must investigate the association between smoking and the incidence of multiple sclerosis, (3) the study must include at least 50 cases, and (4) the study must report the odds ratio (OR), relative risk (RR) with its corresponding $95 \%$ confidence interval $(95 \% \mathrm{CI})$, or the number of events to calculate them.

\section{Study selection and data extraction}

The articles retrieved from the database were independently evaluated by two reviewers 
84 (Peng Zhang and Rui Wang) based on the aforementioned selection criteria. Studies designed as

85

86

87 systematic review and duplicate studies of the same population were excluded. Articles that contained multiple study populations were divided into separate studies. Disagreements were resolved by discussion. Articles in which disagreements could not be resolved were all included. The following information were extracted from the eligible studies: first author, year of publication, country of origin, OR or RR with its $95 \% \mathrm{CI}$, study design, the method of information collection, method of MS diagnosis, and the relationship between disease onset and the duration of smoking.

\section{Statistical analysis}

The rare disease assumption was used to combine the odds ratio (OR) and relative risk (RR)

(Clayton \& Hills 1993). If the RR or OR and its 95\% CI were not reported but sufficient information was available, we used previously described methods to calculate it (Bland \& Altman 2000). Stata12.0 was used to compute the pooled ORs and their $95 \%$ CI, to generate forest plots and to assess the heterogeneity of the included studies. As described in the former meta-analysis (Handel et al. 2011), we also performed this meta-analysis using conservative (including only studies where smoking behavior was described prior to disease onset) and non-conservative (all studies regardless of whether smoking behavior occurred before onset or concurrently) models. To test the stability of the results, we investigated the influence of a single study on the overall effect value by removing one study each time. ORs were calculated among the subgroups of studies and compared across them. Possible publication bias was assessed using Begg's funnel plot and

Egger's test (Begg \& Mazumdar 1994; Egger et al. 1997). 
105

106

107

108

109

110

111

112

113

114

115

116

117

118

119

120

121

122

123

124

125

\section{Results}

\section{Search result and study characteristics}

After selecting studies according to the inclusion criteria, 47 articles considered for further review. Six of these 47 articles could not provide outcome information (Brosseau et al. 1993; Guimond et al. 2014; Lauer 2006; Nortvedt et al. 2005; Senecal-Quevillon et al. 1986; Turner et al. 2007). We could not obtain the full article for 5 of the 47 articles (Dobosz et al. 2012; FrutosAlegria et al. 2002; Frutos Alegria et al. 2002; Ragonese P et al. 2007; Rodriguez Regal et al. 2009). Ten of these 47 articles contained duplicate study populations (Baarnhielm et al. 2012;

Hedstrom et al. 2011a; Hedstrom et al. 2009; Hedstrom et al. 2013a; Hedstrom et al. 2014b;

Hedstrom et al. 2011b; Munger et al. 2009; Munger et al. 2003; Sundqvist et al. 2012; Sundstrom et al. 2008). Ultimately, 26 eligible articles containing 29 study populations were identified (AlAfasy et al. 2013; Alonso et al. 2011; Asadollahi et al. 2013; Briggs et al. 2014; Carlens et al. 2010; Ghadirian et al. 2001; Gustavsen et al. 2014; Hedstrom et al. 2013b; Hernan et al. 2005; Hernan et al. 2001; Jafari et al. 2009; Kotzamani et al. 2012; Maghzi et al. 2011; Mansouri et al. 2014; O'Gorman et al. 2014; Pekmezovic et al. 2006; Ragnedda et al. 2015; Ramagopalan et al. 2013; Riise et al. 2003; Russo et al. 2008; Silva et al. 2009; Simon et al. 2015; Simon et al. 2010; Thorogood \& Hannaford 1998; Villard-Mackintosh \& Vessey 1993; Zorzon et al. 2003). A flow chart for the study selection process was shown in Fig. 1. There were 19,834 cases of MS and 21,350 controls in case-control studies; 792 cases of MS occurred in 601,492 individuals in cohort studies. Among these studies, 4 were conducted in Iran, 4 in America, 3 in England, 3 in Norway, 2 in Canada, 3 in Sweden, 1 in Brazil, 1 in Greece, 2 in Australia, 1 in the Netherlands, 1 in Kuwait, 
126

127

128

129

130

131

132

133

134

135

136

137

138

139

140

141

142

143

144

145

146

3 in Italy, 1 in Serbia. The main characteristics of the included studies are summarized in Table 1.

\section{Smoking and MS susceptibility}

The conservative model contained 24 studies that investigated the association between smoking and MS. Moderate heterogeneity was detected $\left(\mathrm{I}^{2}=37.2 \%, \mathrm{p}=0.035\right)$. As described in Fig. 2, the pooled OR was 1.55 (95\%CI: $1.48-1.62, \mathrm{p}<0.001)$, indicating that ever-smoking increases the risk of MS by 55\% compared with never-smoking individuals. When including all 29 studies in the non-conservative model, we obtained similar results $(\mathrm{OR}=1.57,95 \% \mathrm{CI}: 1.50-1.64, \mathrm{p}<0.001$, heterogeneity: $\mathrm{I}^{2}=47.3 \%, \mathrm{p}=0.003$; Fig. 3 ). There were no significant differences among the subgroups based on study designs, diagnostic criteria, or the data collection methods; however, not adjusting for confounders may overestimate the risk between smoking and MS susceptibility (Table 2).

\section{Different effects of genders and smoking habits}

In total, 10 studies provided enough information to report the association between smoking and MS within genders (Asadollahi et al. 2013; Carlens et al. 2010; Hedstrom et al. 2009; Hernan et al. 2001; Kotzamani et al. 2012; Maghzi et al. 2011; O'Gorman et al. 2014; Simon et al. 2010; Thorogood \& Hannaford 1998; Villard-Mackintosh \& Vessey 1993). Significant differences were detected between different genders $\left(\chi^{2}=11.21, p=0.001\right.$, Fig. 4). Smoking in men is more dangerous than women. Similarly, we included 7 studies that provided data about the effects of different smoking habits on susceptibility to MS (Carlens et al. 2010; Hedstrom et al. 2013a; 
147 Hernan et al. 2005; Hernan et al. 2001; Jafari et al. 2009; O'Gorman et al. 2014; Zorzon et al. 148 2003). Being a current smoker increases the risk of MS by $83 \%$ risk compared with nonsmokers; 149 past smoking increases the risk of MS by 58\% compared with nonsmokers. Significant differences 150 were detected between the effects of current and past smoking versus non-smokers $\left(\chi^{2}=12.66\right.$, $\mathrm{p}<0.001$, Fig. 5). In order to explore the impact of passive smoking (active smokers were excluded) on the risk of MS, we identified 3 eligible articles containing 4 study populations (Hedstrom et al. 2014a; Hedstrom et al. 2013b; Ramagopalan et al. 2013). As described in Fig. 6, the pooled OR was 1.24 (95\%CI: $1.03-1.49, \mathrm{p}=0.028)$, indicating that exposure to passive smoking increases the risk of MS by $24 \%$ compared with unexposed individuals.

\section{Sensitivity analysis and publication bias}

Fig. 7 implied the funnel plot was symmetrical, suggesting no publication bias. The Begg

rank correction test and Egger linear regression showed no asymmetry (Begg, p=0.612; Egger, $\mathrm{p}=0.204)$.

Fig. 8 showed the result of the sensitivity analysis by removing one study in each turn. This procedure showed that the study by Hedstrom in 2013 significantly impacted the main result. When switched from fixed effects model to random effects model, the OR changed from 1.57 (95\%CI: $1.50-1.64, \mathrm{p}<0.001)$ to $1.63(95 \% \mathrm{CI}: 1.51-1.76, \mathrm{p}<0.001)$, suggesting that the result was robustness. 
167

168

169

170

171

172

173

174

175

176

177

178

179

180

181

182

183

184

185

186

187

\section{Discussion}

Our meta-analysis showed there was a strong association between smoking and MS susceptibility. Ever-smoking could increase the risk of MS by a more than $50 \%$ risk compared with never-smoking population. The non-conservative model obtained a similar result compared with the conservative model, suggesting a robustness of the results. The subgroup analyses showed that different study designs, diagnostic criteria and types of information resource had little impact on the relationship between smoking and MS susceptibility. However, inadequate adjustment may overestimate the risk between smoking and MS susceptibility. The sensitivity analysis showed the study by Hedstrom 2013 significantly impacted the main result. Therefore, we reviewed this article and found that it included 6990 cases (no snuff use) and 8279 controls (no snuff use) that constituted $46.32 \%$ of the entire meta-analysis. Male smokers were shown to have a higher risk of developing MS than female, but the exact number of cigarettes consumed by different genders per day due to different lifestyle habits was unavailable, so we were unable to draw a firm conclusion.

Significant differences were detected between the effects of current and former smokers compared with non-smokers. Current smoking is more dangerous than past smoking, which informed individuals of the benefits of smoking cessation. Passive smoking is a risk factor for MS in nonsmoking population. Smoke-free environment in public places and home is vital to people's health. Comparing with three former meta-analyses (Hawkes 2007 (OR=1.34), Handel 2011 $(\mathrm{OR}=1.52)$, O'Gorman $2014(\mathrm{OR}=1.51))$, our study obtained a greater effect estimates between smoking and MS susceptibility (OR=1.57) (Handel et al. 2011; Hawkes 2007; O'Gorman \& Broadley 2014). Studies published from 2013 to 2015 accounted for $78.62 \%$ of the entire meta- 
188

189

190

191

192

193

194

195

196

197

198

199

200

201

202

203

204

205

206

207

208

analysis and reported higher effect estimates.

The etiology of MS is still unknown, and both genetic and environmental factors may contribute to this disease (Compston \& Coles 2008). MS is more common with the increasing latitude, except for some ethnic groups such as the New Zealand Moori (Pugliatti et al. 2002), Canada's Inuit (Milo \& Kahana 2010) and inland Sicilians (Grimaldi et al. 2001); however, the reasons for these geographical distributions are still controversial (Milo \& Kahana 2010). Some people believe that a possible explanation could be that decreased exposure to sunlight results in decreased levels of vitamin D (Ascherio \& Munger 2007; Ascherio et al. 2010), while others believe that it is a consequence of the distribution of the northern European populations that had a high prevalence of MS (Milo \& Kahana 2010). Although MS is not considered to be a hereditary disease, the probability of MS is higher if there is a family history of the disease (Compston \& Coles 2002). Differences of specific genes in the human leukocyte antigen (HLA) system that serve as the major histocompatibility complex (MHC) may be associated with MS susceptibility (Compston \& Coles 2008).

The causal link between cigarette smoking and MS is still unclear (Jafari \& Hintzen 2011). There are more than 4500 types of possible toxic substances, including nicotine and nitric oxide in cigarette smoke. Some nerve lesions, such as axonal degeneration, have been caused by exposure to nitric oxide (Scolding \& Franklin 1998; Smith et al. 1999). A study in Sweden showed the inhalation of non-nicotinic components of cigarette smoke are more influential than nicotine in the etiology of MS (Carlens et al. 2010). This finding suggests the real reason for the elevated risk of MS is the irritation of cigarette smoke in the lungs, triggering the pro-inflammatory effect 
209 of smoking via toll-like receptors (Mortaz et al. 2009; Pace et al. 2008). As a type of lymphocyte,

210 T-cells enter the brain by destroying the blood-brain barrier in the inflammatory process. The T-

211 cell recognized myelin as exogenous material and attacked it, causing the loss of myelin

212 (Compston \& Coles 2008). Further damage of the blood-brain barrier will lead to a number of

213 other effects, such as the activation of cytokines and modification of proteins that may break self-

214 tolerance, resulting in autoimmune responses against antigens of the nervous system

215 (Makrygiannakis et al. 2008).

216 Most of the studies included in this meta-analysis focus on the risk of MS between having

217 ever smoked and never smoking; however, the exact dose of cigarette consumption as well as how

218 these data were recorded vary from study to study (pack-years, per day etc.). Therefore, it is

219 difficult to assess the association between the degree of MS susceptibility and the degree of

220 cigarette consumption based on current studies.

\section{Conclusions}

222 Our meta-analysis suggests that exposure to smoking is an important risk factor for MS.

223 People would benefit from quitting smoking, and policymakers should pay attention to this

224 association. Further research is needed to assess the dose-response effect between smoking and

225 MS.

226 Acknowledgments

227 None.

228

References 
230

231

232

233

234

235

236

237

238

239

240

241

242

243

244

245

246

247

248

249

250

251

252

253

254

255

256

257

258

259

260

261

262

263

264

265

266

267

268

269

270

factors for multiple sclerosis in Kuwait: a population-based case-control study. Neuroepidemiology 40:3035.

Alonso A, Cook SD, Maghzi AH, and Divani AA. 2011. A case-control study of risk factors for multiple sclerosis in Iran. Mult Scler 17:550-555.

Asadollahi S, Fakhri M, Heidari K, Zandieh A, Vafaee R, and Mansouri B. 2013. Cigarette smoking and associated risk of multiple sclerosis in the Iranian population. J Clin Neurosci 20:1747-1750.

Ascherio A, and Munger KL. 2007. Environmental risk factors for multiple sclerosis. Part II: Noninfectious factors. Ann Neurol 61:504-513.

Ascherio A, Munger KL, and Simon KC. 2010. Vitamin D and multiple sclerosis. Lancet Neurol 9:599-612.

Baarnhielm M, Hedstrom AK, Kockum I, Sundqvist E, Gustafsson SA, Hillert J, Olsson T, and Alfredsson L. 2012. Sunlight is associated with decreased multiple sclerosis risk: no interaction with human leukocyte antigenDRB1*15. Eur J Neurol 19:955-962.

Begg CB, and Mazumdar M. 1994. Operating characteristics of a rank correlation test for publication bias. Biometrics 50:1088-1101.

Bland JM, and Altman DG. 2000. Statistics notes. The odds ratio. Bmj 320:1468.

Briggs FB, Acuna B, Shen L, Ramsay P, Quach H, Bernstein A, Bellesis KH, Kockum IS, Hedstrom AK, Alfredsson L et al. . 2014. Smoking and risk of multiple sclerosis: evidence of modification by NAT1 variants. Epidemiology 25:605-614.

Brosseau L, Philippe P, Methot G, Duquette P, and Haraoui B. 1993. Drug abuse as a risk factor of multiple sclerosis: case-control analysis and a study of heterogeneity. Neuroepidemiology 12:6-14.

Carlens C, Hergens MP, Grunewald J, Ekbom A, Eklund A, Hoglund CO, and Askling J. 2010. Smoking, use of moist snuff, and risk of chronic inflammatory diseases. Am J Respir Crit Care Med 181:1217-1222.

Clayton D, and Hills M. 1993. Statistical models in epidemiology. Oxford: Oxford University Press.

Collaborators. GMaCoD. 2015. Global, regional, and national age-sex specific all-cause and cause-specific mortality for 240 causes of death, 1990-2013: a systematic analysis for the Global Burden of Disease Study 2013. Lancet 385:117-171.

Compston A, and Coles A. 2002. Multiple sclerosis. Lancet 359:1221-1231.

Compston A, and Coles A. 2008. Multiple sclerosis. Lancet 372:1502-1517.

Dobosz C, Tyrpien K, and Pierzchala K. 2012. [Assessment of exposure to tobacco smoke in a selected group of patients with multiple sclerosis from the Upper Silesia region]. Przegl Lek 69:940-943.

Egger M, Davey Smith G, Schneider M, and Minder C. 1997. Bias in meta-analysis detected by a simple, graphical test. Bmj 315:629-634.

Frutos-Alegria MT, Beltran-Blasco I, Quilez-Iborra C, Molto-Jorda J, Diaz-Marin C, and Matias-Guiu J. 2002. [A control and case study of multiple sclerosis in the Alicante and Villajoyosa areas]. Rev Neurol 34:1013-1016.

Frutos Alegria MT, Beltran-Blasco I, Quilez-Iborra C, Molto-Jorda J, Diaz-Marin C, and Matias-Guiu J. 2002. [The epidemiology of multiples sclerosis in Alcoi. Analytical data]. Rev Neurol 34:813-816.

Ghadirian P, Dadgostar B, Azani R, and Maisonneuve P. 2001. A case-control study of the association between sociodemographic, lifestyle and medical history factors and multiple sclerosis. Can J Public Health 92:281-285.

Grimaldi LM, Salemi G, Grimaldi G, Rizzo A, Marziolo R, Lo Presti C, Maimone D, and Savettieri G. 2001. High incidence and increasing prevalence of MS in Enna (Sicily), southern Italy. Neurology 57:1891-1893.

Guimond C, Lee JD, Ramagopalan SV, Dyment DA, Hanwell H, Giovannoni G, Criscuoli M, Yee IM, Vorobeychik G, 
Ebers GC et al. . 2014. Multiple sclerosis in the Iranian immigrant population of BC, Canada: prevalence and risk factors. Mult Scler.

Gustavsen MW, Page CM, Moen SM, Bjolgerud A, Berg-Hansen P, Nygaard GO, Sandvik L, Lie BA, Celius EG, and Harbo HF. 2014. Environmental exposures and the risk of multiple sclerosis investigated in a Norwegian case-control study. BMC Neurol 14:196.

Handel AE, Handunnetthi L, Giovannoni G, Ebers GC, and Ramagopalan SV. 2010. Genetic and environmental factors and the distribution of multiple sclerosis in Europe. Eur J Neurol 17:1210-1214.

Handel AE, Williamson AJ, Disanto G, Dobson R, Giovannoni G, and Ramagopalan SV. 2011. Smoking and multiple sclerosis: an updated meta-analysis. PLoS One 6:e16149.

Hawkes CH. 2007. Smoking is a risk factor for multiple sclerosis: a metanalysis. Mult Scler 13:610-615.

Hedstrom AK, Akerstedt T, Hillert J, Olsson T, and Alfredsson L. 2011a. Shift work at young age is associated with increased risk for multiple sclerosis. Ann Neurol 70:733-741.

Hedstrom AK, Baarnhielm M, Olsson T, and Alfredsson L. 2009. Tobacco smoking, but not Swedish snuff use, increases the risk of multiple sclerosis. Neurology 73:696-701.

Hedstrom AK, Bomfim IL, Barcellos LF, Briggs F, Schaefer C, Kockum I, Olsson T, and Alfredsson L. 2014a. Interaction between passive smoking and two HLA genes with regard to multiple sclerosis risk. Int J Epidemiol 43:17911798.

Hedstrom AK, Hillert J, Olsson T, and Alfredsson L. 2013a. Nicotine might have a protective effect in the etiology of multiple sclerosis. Mult Scler 19:1009-1013.

Hedstrom AK, Hillert J, Olsson T, and Alfredsson L. 2013b. Smoking and multiple sclerosis susceptibility. Eur J Epidemiol 28:867-874.

Hedstrom AK, Hillert J, Olsson T, and Alfredsson L. 2014b. Alcohol as a modifiable lifestyle factor affecting multiple sclerosis risk. JAMA Neurol 71:300-305.

Hedstrom AK, Sundqvist E, Baarnhielm M, Nordin N, Hillert J, Kockum I, Olsson T, and Alfredsson L. 2011b. Smoking and two human leukocyte antigen genes interact to increase the risk for multiple sclerosis. Brain 134:653664.

Hernan MA, Jick SS, Logroscino G, Olek MJ, Ascherio A, and Jick H. 2005. Cigarette smoking and the progression of multiple sclerosis. Brain 128:1461-1465.

Hernan MA, Olek MJ, and Ascherio A. 2001. Cigarette smoking and incidence of multiple sclerosis. Am J Epidemiol 154:69-74.

Jafari N, and Hintzen RQ. 2011. The association between cigarette smoking and multiple sclerosis. J Neurol Sci 311:78-85.

Jafari N, Hoppenbrouwers IA, Hop WC, Breteler MM, and Hintzen RQ. 2009. Cigarette smoking and risk of MS in multiplex families. Mult Scler 15:1363-1367.

Kotzamani D, Panou T, Mastorodemos V, Tzagournissakis M, Nikolakaki H, Spanaki C, and Plaitakis A. 2012. Rising incidence of multiple sclerosis in females associated with urbanization. Neurology 78:1728-1735.

Lauer K. 2006. Divergent risk of multiple sclerosis in two anabaptist communities in America. Med Hypotheses 67:969-974.

Maghzi AH, Etemadifar M, Heshmat-Ghahdarijani K, Moradi V, Nonahal S, Ghorbani A, and Minagar A. 2011. Cigarette smoking and the risk of multiple sclerosis: a sibling case-control study in Isfahan, Iran. Neuroepidemiology 37:238-242. 
312

313

314

315

316

317

318

319

320

321

322

323

324

325

326

327

328

329

330

331

332

333

334

335

336

337

338

339

340

341

342

343

344

345

346

347

348

349

350

351

352

Makrygiannakis D, Hermansson M, Ulfgren AK, Nicholas AP, Zendman AJ, Eklund A, Grunewald J, Skold CM, Klareskog L, and Catrina AI. 2008. Smoking increases peptidylarginine deiminase 2 enzyme expression in human lungs and increases citrullination in BAL cells. Ann Rheum Dis 67:1488-1492.

Mansouri B, Asadollahi S, Heidari K, Fakhri M, Assarzadegan F, Nazari M, and Divani A. 2014. Risk factors for increased multiple sclerosis susceptibility in the Iranian population. J Clin Neurosci 21:2207-2211.

Milo R, and Kahana E. 2010. Multiple sclerosis: geoepidemiology, genetics and the environment. Autoimmun Rev 9:A387-394.

Mortaz E, Lazar Z, Koenderman L, Kraneveld AD, Nijkamp FP, and Folkerts G. 2009. Cigarette smoke attenuates the production of cytokines by human plasmacytoid dendritic cells and enhances the release of IL-8 in response to TLR-9 stimulation. Respir Res 10:47.

Munger KL, Chitnis T, and Ascherio A. 2009. Body size and risk of MS in two cohorts of US women. Neurology 73:15431550.

Munger KL, Peeling RW, Hernan MA, Chasan-Taber L, Olek MJ, Hankinson SE, Hunter D, and Ascherio A. 2003. Infection with Chlamydia pneumoniae and risk of multiple sclerosis. Epidemiology 14:141-147.

Nortvedt MW, Riise T, and Maeland JG. 2005. Multiple sclerosis and lifestyle factors: the Hordaland Health Study. Neurol Sci 26:334-339.

O'Gorman C, and Broadley SA. 2014. Smoking and multiple sclerosis: evidence for latitudinal and temporal variation. J Neurol 261:1677-1683.

O'Gorman C, Bukhari W, Todd A, Freeman S, and Broadley SA. 2014. Smoking increases the risk of multiple sclerosis in Queensland, Australia. J Clin Neurosci 21:1730-1733.

Pace E, Ferraro M, Siena L, Melis M, Montalbano AM, Johnson M, Bonsignore MR, Bonsignore G, and Gjomarkaj M. 2008. Cigarette smoke increases Toll-like receptor 4 and modifies lipopolysaccharide-mediated responses in airway epithelial cells. Immunology 124:401-411.

Pekmezovic T, Drulovic J, Milenkovic M, Jarebinski M, Stojsavljevic N, Mesaros S, Kisic D, and Kostic J. 2006. Lifestyle factors and multiple sclerosis: A case-control study in Belgrade. Neuroepidemiology 27:212-216.

Pugliatti M, Sotgiu S, and Rosati G. 2002. The worldwide prevalence of multiple sclerosis. Clin Neurol Neurosurg 104:182-191.

Ragnedda G, Leoni S, Parpinel M, Casetta I, Riise T, Myhr KM, Wolfson C, and Pugliatti M. 2015. Reduced duration of breastfeeding is associated with a higher risk of multiple sclerosis in both Italian and Norwegian adult males: the EnvIMS study. J Neurol 262:1271-1277.

Ragonese P, Castiglia G, Cusimano V, Battaglieri F, and G S. 2007. Cigarette smoking, coffee consumption and multiple sclerosis risk: a case-control study. ACTA MEDICA MEDITERRANEA 23:133-140.

Ramagopalan SV, Lee JD, Yee IM, Guimond C, Traboulsee AL, Ebers GC, and Sadovnick AD. 2013. Association of smoking with risk of multiple sclerosis: a population-based study. J Neurol 260:1778-1781.

Ramagopalan SV, Maugeri NJ, Handunnetthi L, Lincoln MR, Orton SM, Dyment DA, Deluca GC, Herrera BM, Chao MJ, Sadovnick AD et al. . 2009. Expression of the multiple sclerosis-associated MHC class II Allele HLADRB1*1501 is regulated by vitamin D. PLoS Genet 5:e1000369.

Riise T, Nortvedt MW, and Ascherio A. 2003. Smoking is a risk factor for multiple sclerosis. Neurology 61:1122-1124.

Rodriguez Regal A, del Campo Amigo M, Paz-Esquete J, Martinez Feijoo A, Cebrian E, Suarez Gil P, and Mourino MA. 2009. [A case-control study of the influence of the smoking behaviour in multiple sclerosis]. Neurologia 24:177-180.

Peer] reviewing PDF | (2015:10:7134:2:0:NEW 19 Feb 2016) 
Russo C, Morabito F, Luise F, Piromalli A, Battaglia L, Vinci A, Trapani Lombardo V, de Marco V, Morabito P, Condino F et al. . 2008. Hyperhomocysteinemia is associated with cognitive impairment in multiple sclerosis. J Neurol 255:64-69.

Scolding N, and Franklin R. 1998. Axon loss in multiple sclerosis. Lancet 352:340-341.

Senecal-Quevillon M, Duquette P, and Richer CL. 1986. Analysis of sister-chromatid exchanges (SCEs) in familial and sporadic multiple sclerosis. Mutat Res 161:65-74.

Silva KR, Alvarenga RM, Fernandez YFO, Alvarenga $\mathrm{H}$, and Thuler LC. 2009. Potential risk factors for multiple sclerosis in Rio de Janeiro: a case-control study. Arq Neuropsiquiatr 67:229-234.

Simon KC, O'Reilly EJ, Munger KL, Finerty S, Morgan AJ, and Ascherio A. 2012. Epstein-Barr virus neutralizing antibody levels and risk of multiple sclerosis. Mult Scler 18:1185-1187.

Simon KC, Schmidt H, Loud S, and Ascherio A. 2015. Risk factors for multiple sclerosis, neuromyelitis optica and transverse myelitis. Mult Scler 21:703-709.

Simon KC, van der Mei IA, Munger KL, Ponsonby A, Dickinson J, Dwyer T, Sundstrom P, and Ascherio A. 2010. Combined effects of smoking, anti-EBNA antibodies, and HLA-DRB1*1501 on multiple sclerosis risk. Neurology 74:1365-1371.

Smith KJ, Kapoor R, and Felts PA. 1999. Demyelination: the role of reactive oxygen and nitrogen species. Brain Pathol 9:69-92.

Sundqvist E, Sundstrom P, Linden M, Hedstrom AK, Aloisi F, Hillert J, Kockum I, Alfredsson L, and Olsson T. 2012. Lack of replication of interaction between EBNA1 IgG and smoking in risk for multiple sclerosis. Neurology 79:1363-1368.

Sundstrom P, Nystrom L, and Hallmans G. 2008. Smoke exposure increases the risk for multiple sclerosis. Eur J Neurol 15:579-583.

Thorogood M, and Hannaford PC. 1998. The influence of oral contraceptives on the risk of multiple sclerosis. $\mathrm{Br} \mathrm{J}$ Obstet Gynaecol 105:1296-1299.

Turner AP, Kivlahan DR, Kazis LE, and Haselkorn JK. 2007. Smoking among veterans with multiple sclerosis: prevalence correlates, quit attempts, and unmet need for services. Arch Phys Med Rehabil 88:1394-1399.

Villard-Mackintosh L, and Vessey MP. 1993. Oral contraceptives and reproductive factors in multiple sclerosis incidence. Contraception 47:161-168.

WHO. 2013. Atlas: Multiple Sclerosis Resources in the World.Geneva: World Health Organization.

Zorzon M, Zivadinov R, Nasuelli D, Dolfini P, Bosco A, Bratina A, Tommasi MA, Locatelli L, and Cazzato G. 2003. Risk factors of multiple sclerosis: a case-control study. Neurol Sci 24:242-247. 
1

Summary of the Studies Selection Process.

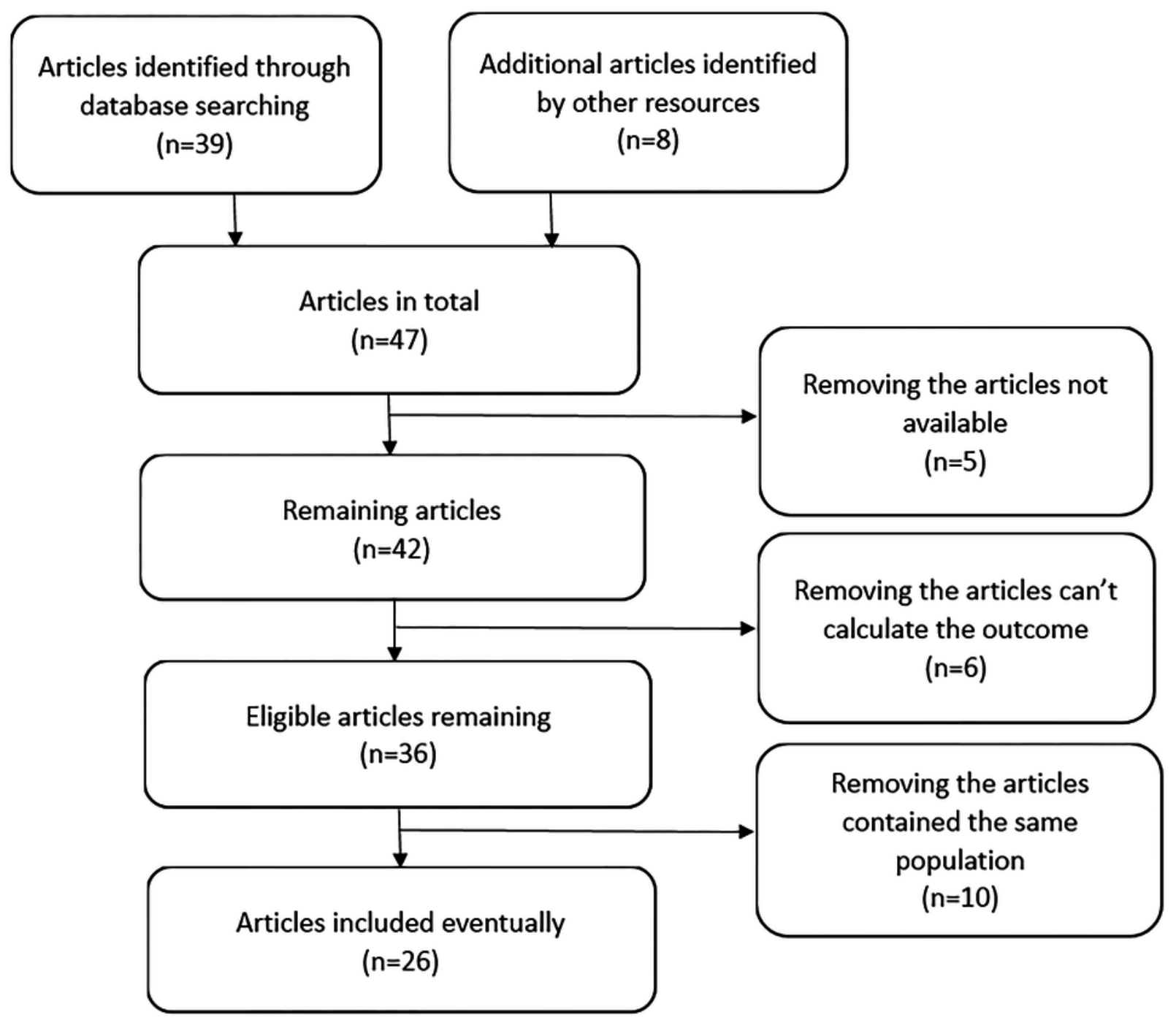


2

Forest Plot of Smoking and Multiple Sclerosis Risk (conservative model).

Study

ID

OR $(95 \% \mathrm{Cl}) \quad$ Weight(\%)

Ragnedda 2015(Nonwegian)

Ragnedda 2015(Italian)

Simon 2014

Mansouri 2014

Briggs 2014

Hedstrom 2013

Asadollahi 2013

Al-Afasy 2012

Kotzamani 2012

Maghzi 2011

Alonso 2011

Carlens 2010

Simon 2010(Nurses' Health Studies)

Simon 2010(Tasmanian MS Study)

Simon 2010(Swedish MS Study)

Jafari 2009

Pekmezovic 2006

Hernan 2005

Zorzon 2003

Riise 2003

Ghadirian 2001

Hernan 2001

Thorogood 1998

Villard 1993

\begin{tabular}{c|cc} 
Overall $($ l-squared $=37.2 \%, p=0.035)$ & 0 & \multicolumn{1}{c}{1} \\
\hline 238 & 1 & 4.21
\end{tabular}

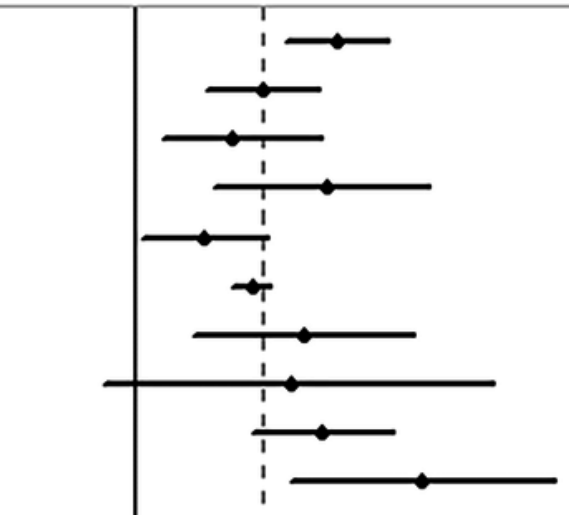

$2.00(1.68,2.38) \quad 7.06$

$1.55(1.28,1.88) \quad 5.79$

$1.40(1.10,1.90) \quad 2.87$

$1.93(1.31,2.73) \quad 1.59$

$1.27(1.03,1.58) \quad 4.68$

$1.49(1.40,1.59) \quad 52.85$

$1.78(1.22,2.59) \quad 1.51$

$1.70(0.90,3.40) \quad 0.48$

$1.90(1.50,2.41) \quad 3.81$

$2.67(1.70,4.21) \quad 1.04$

$1.72(0.90,3.30) \quad 0.51$

$2.50(1.70,3.60) \quad 1.52$

$1.40(1.00,2.00) \quad 1.78$

$1.50(1.00,2.40) \quad 1.12$

$1.40(0.80,2.40) \quad 0.71$

$1.09(0.68,1.73) \quad 0.98$

$1.60(1.08,2.37) \quad 1.39$

$1.30(1.00,1.70) \quad 3.04$

$1.50(0.90,2.40) \quad 0.89$

$1.81(1.13,2.92) \quad 0.95$

$1.60(1.00,2.40) \quad 1.12$

$1.60(1.20,2.10) \quad 2.73$

$1.20(0.80,1.80) \quad 1.30$

$1.50(0.60,3.30) \quad 0.29$

$1.55(1.48,1.62) \quad 100.00$ 
3

Forest Plot of Smoking and Multiple Sclerosis Risk (non-conservative model).

Study

ID

OR $(95 \% \mathrm{Cl}) \quad$ Weight(\%)

Ragnedda 2015 (Nowwegian)

Ragnedda 2015 (Italian)

Simon 2014

Gustavsen 2014

Mansouri 2014

O'Gorman 2014

Briggs 2014

Hedstrom 2013

Asadollahi 2013

Ramagopalan 2013

Al-Afasy 2012

Kotzamani 2012

Maghzi 2011

Alonso 2011

Carlens 2010

Simon 2010(Nurses' Health Studies)

Simon 2010(Tasmanian MS Study)

Simon 2010(Swedish MS Study)

Jafari 2009

Silva 2009

Russo 2008

Pekmezovic 2006

Hernan 2005

Zorzon 2003

Riise 2003

Ghadirian 2001

Hernan 2001

Thorogood 1998

Villard 1993

Overall (l-squared $=47.3 \%, p=0.003$ )

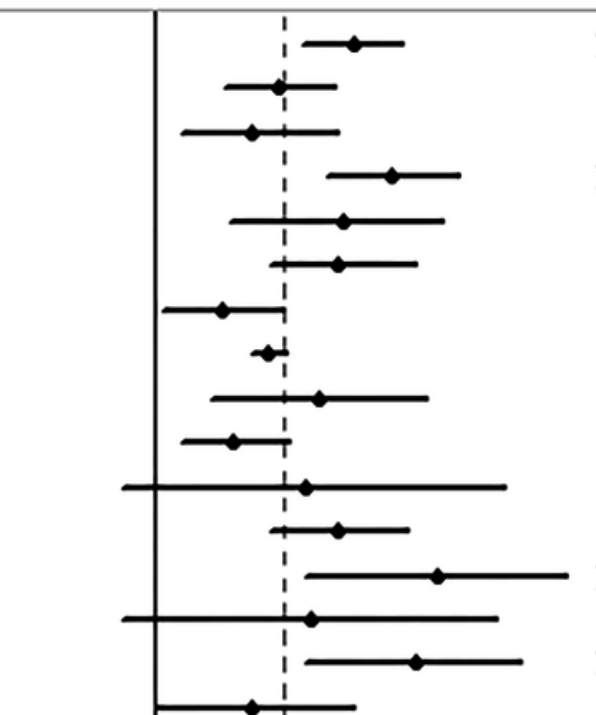

$2.00(1.68,2.38) \quad 6.18$

$1.55(1.28,1.88) \quad 5.08$

$1.40(1.10,1.90) \quad 2.51$

$2.29(1.82,2.89) \quad 3.51$

$1.93(1.31,2.73) \quad 1.39$

$1.90(1.50,2.50) \quad 2.87$

$1.27(1.03,1.58) \quad 4.10$

$1.49(1.40,1.59) \quad 46.32$

$1.78(1.22,2.59) \quad 1.32$

$1.32(1.10,1.60) \quad 5.34$

$1.70(0.90,3.40) \quad 0.42$

$1.90(1.50,2.41) \quad 3.34$

$2.67(1.70,4.21) \quad 0.91$

$1.72(0.90,3.30) \quad 0.44$

$2.50(1.70,3.60) \quad 1.33$

$1.40(1.00,2.00) \quad 1.56$

$1.50(1.00,2.40) \quad 0.98$

$1.40(0.80,2.40) \quad 0.62$

$1.09(0.68,1.73) \quad 0.86$

$2.00(0.90,4.30) \quad 0.31$

$1.83(0.86,3.87) \quad 0.33$

$1.60(1.08,2.37) \quad 1.21$

$1.30(1.00,1.70) \quad 2.66$

$1.50(0.90,2.40) \quad 0.78$

$1.81(1.13,2.92) \quad 0.83$

$1.60(1.00,2.40) \quad 0.98$

$1.60(1.20,2.10) \quad 2.40$

$1.20(0.80,1.80) \quad 1.14$

$1.50(0.60,3.30) \quad 0.26$

$1.57(1.50,1.64) \quad 100.00$

\begin{tabular}{cccc}
1 & & 1 & \\
\hline 233 & 1 & 4.3
\end{tabular}


4

Forest Plot of Smoking and Risk of Multiple Sclerosis in different Genders.

Study

ID

OR $(95 \% \mathrm{Cl}) \quad$ Weight(\%)

male

Asadollahi 2013

Kotzamani 2012

Maghzi 2011

Carlens 2010

Hedstrom 2009

O'Gorman 2014

Subtotal (l-squared $=0.0 \%, p=0.850$ )

female

Asadollahi 2013

Kotzamani 2012

Simon 2010(Nurses's Health Studies)

Hedstrom 2009

Hernan 2001

Villard 1993

Thorogood 1998

O'Gorman 2014

Subtotal (l-squared $=0.0 \%, p=0.716$ )

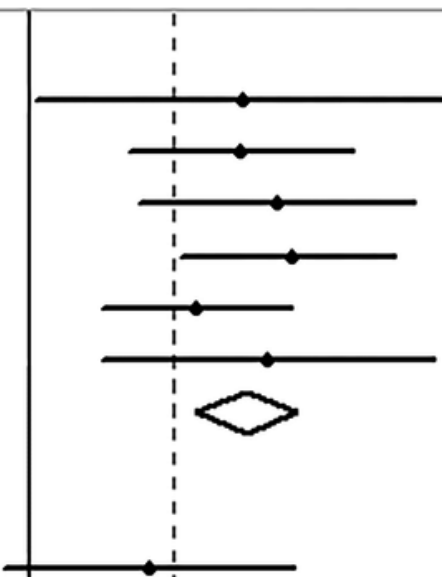

$2.12(1.03,4.35) 1.63$

$2.10(1.42,3.11) 5.51$

$2.38(1.47,3.85) \quad 3.65$

$2.50(1.70,3.60) 6.01$

$1.80(1.30,2.50) 7.92$

$2.30(1.30,4.10) 2.57$

$2.14(1.80,2.55) 27.29$

$1.53(0.92,2.52) \quad 3.33$

$1.77(1.26,2.50) 7.21$

$1.40(1.00,2.00) 7.05$

$1.40(1.20,1.70) 27.91$

$1.60(1.20,2.10) \quad 10.81$

$1.50(0.60,3.30) 1.17$

$1.20(0.80,1.80) 5.15$

$1.80(1.40,2.50) \quad 10.07$

$1.50(1.35,1.68) 72.71$

Heterogeneity between groups: $p=0.001$

Overall (l-squared $=26.7 \%, p=0.167$ )

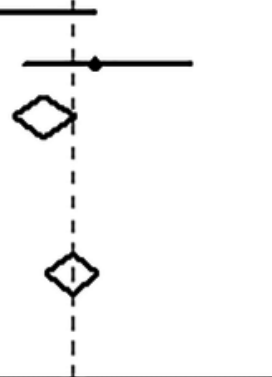

$1.66(1.51,1.82) \quad 100.00$ 


\section{5}

Forest Plot of Smoking and Risk of Multiple Sclerosis in Different Smoking Habits.

Study

ID

OR $(95 \% \mathrm{Cl}) \quad$ Weight(\%)

current smoking

O'Gorman 2014

Hedstrom 2013

Jafari 2009

Hernan 2005

Hernan 2001

Carlens 2010

Zorzon 2003

Subtotal (I-squared $=81.1 \%, p=0.000)$

past smoking

O'Gorman 2014

Hedstrom 2013

Jafari 2009

Hernan 2005

Hernan 2001

Carlens 2010

Subtotal (I-squared $=0.0 \%, p=0.592$ )

Heterogeneity between groups: $p<0.001$

Overall (I-squared $=75.1 \%, p=0.000$ )

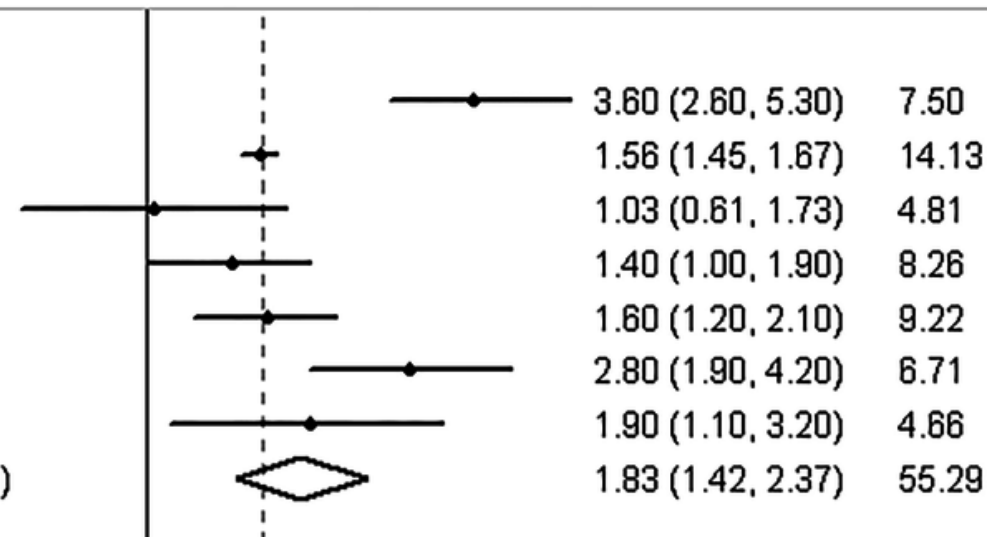

$1.60(1.20,2.10) \quad 9.22$

$1.35(1.24,1.47) \quad 13.91$

$1.19(0.64,2.20) \quad 3.79$

$1.00(0.60,1.80) \quad 4.48$

$1.20(0.90,1.60) \quad 9.03$

$1.60(0.90,2.80) \quad 4.28$

$1.35(1.25,1.46) \quad 44.71$

$1.58(1.38,1.82) \quad 100.00$

\begin{tabular}{c|ccc} 
& & $1.58(1.38,1.82)$ & 100.00 \\
.189 & 1 & 5.3
\end{tabular}


6

Forest Plot of Passive Smoking and Multiple Sclerosis Risk

Study

ID

OR $(95 \% \mathrm{Cl})$

Weight(\%)

Ramagopalan 2013

Hedstrom(EIMS) 2014

Hedstrom(KPNC) 2014

Hedstrom(GEMS) 2013

Overall $(I-$ squared $=67.0 \%, p=0.028$ )

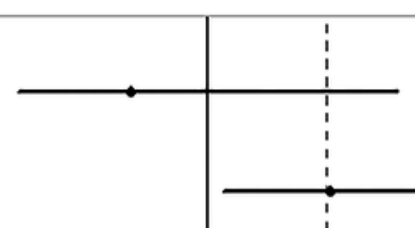

$0.87(0.71,1.41)$

16.46

$1.25(1.03,1.51)$

27.58

$1.67(1.28,2.18)$

21.45

$1.21(1.08,1.35)$

34.52

$1.24(1.03,1.49) \quad 100.00$ 
7

Funnel Plot Based on Related Risk for Association between Smoking and Multiple Sclerosis

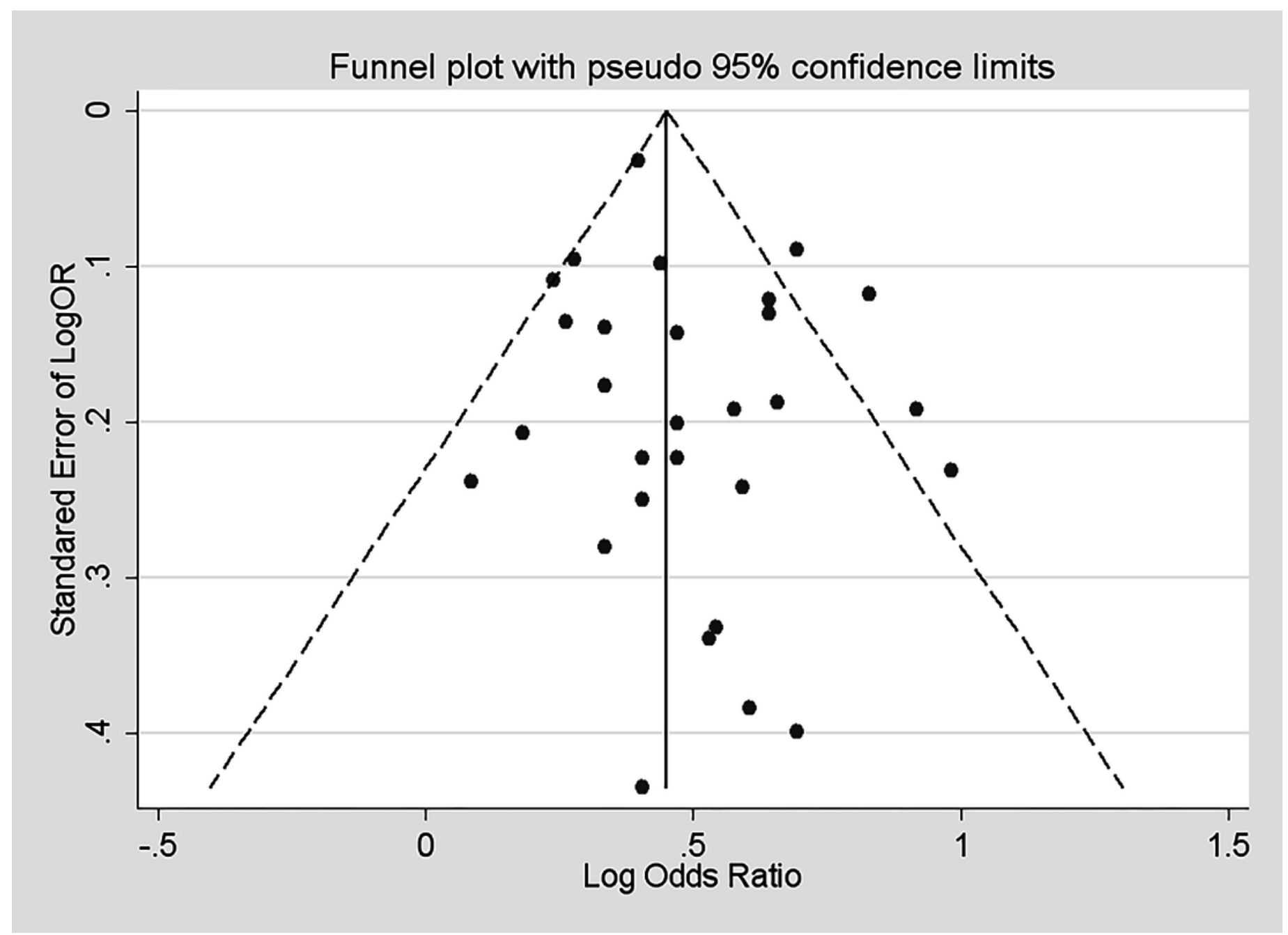


8

Forest Plot of Sensitivity Analysis by Removing Each Study in Each Turn

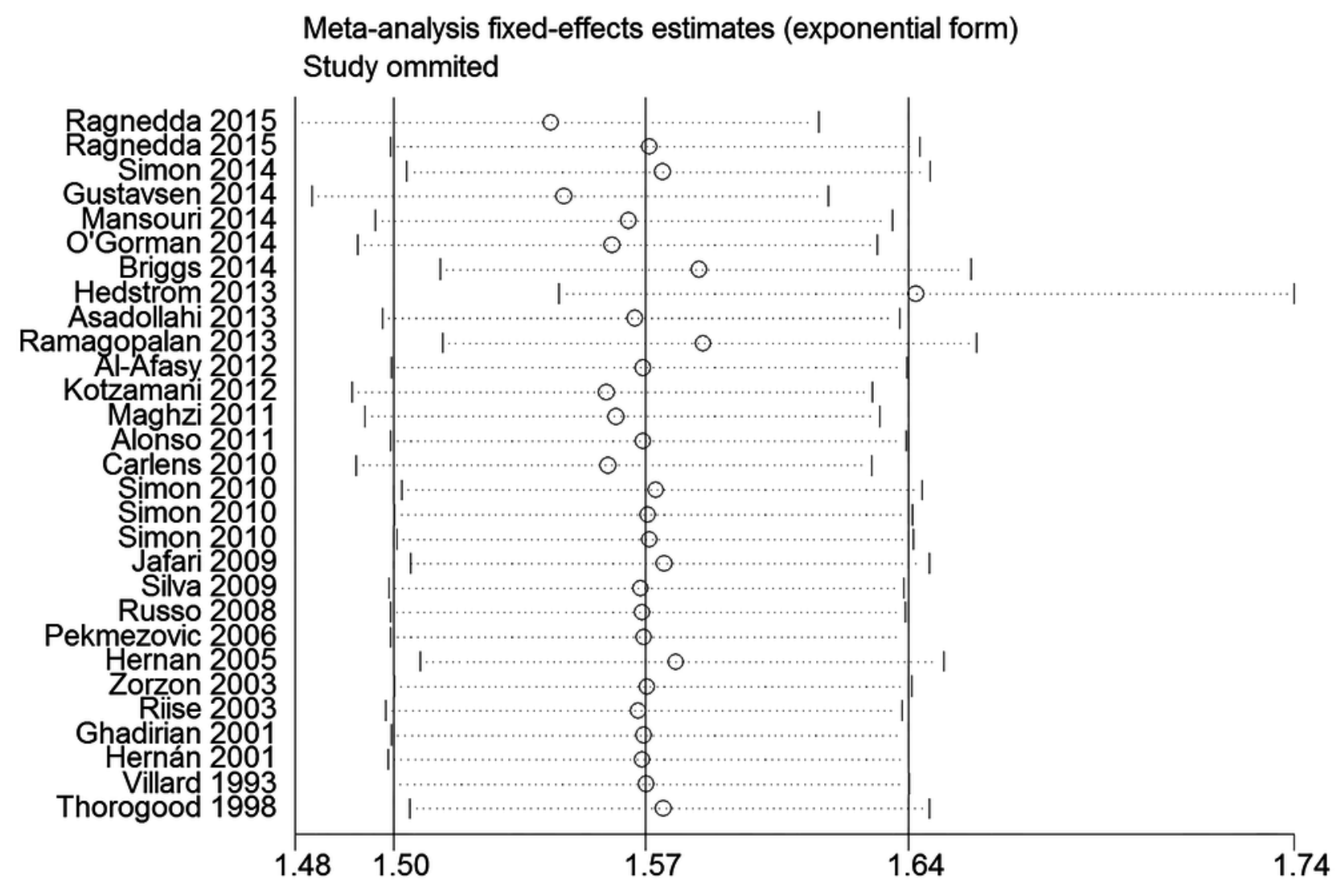




\section{Table 1 (on next page)}

The main characteristics of the included studies. 


\begin{tabular}{|c|c|c|c|c|c|c|c|}
\hline $\begin{array}{l}1^{\text {st }} \text { author and } \\
\text { year of } \\
\text { publication }\end{array}$ & cases & $\begin{array}{l}\text { Controls or } \\
\text { observational } \\
\text { individual }\end{array}$ & $\begin{array}{c}\text { OR or } \mathrm{RR}(95 \% \mathrm{CI}) \\
\text { Versus never-smoking }\end{array}$ & $\begin{array}{l}\text { Information } \\
\text { collecting }\end{array}$ & Type & Diagnostic criteria & $\begin{array}{l}\text { Smoking and } \\
\text { the onset of } \\
\text { MS }\end{array}$ \\
\hline $\begin{array}{l}\text { Ragnedda2015 } \\
\text { (Norwegian) }\end{array}$ & 894 & 1610 & $2.00(1.68,2.38)[$ ever-smoking $]$ & questionnaire & case-control & McDonald & before onset \\
\hline $\begin{array}{l}\text { Ragnedda2015 } \\
\text { (Italian) }\end{array}$ & 617 & 1161 & $1.55(1.28,1.88)[$ ever-smoking] & questionnaire & case-control & McDonald & before onset \\
\hline Simon 2014 & 1190 & 454 & 1.4(1.1,1.9)[ ever-smoking] & face interview & case-control & N/A & before onset \\
\hline Gustavsen 2014 & 530 & 918 & $2.29(1.82,2.89)[$ ever-smoking] & questionnaire & case-control & McDonald or Poser & current \\
\hline Mansouri 2014 & 1217 & 787 & 1.93(1.31,2.73)[ ever-smoking] & face interview & case-control & McDonald or Poser & before onset \\
\hline O'Gorman 2014 & 560 & 480 & $\begin{array}{l}1.9(1.5,2.5)[\text { ever-smoking }] \\
3.6(2.3,5.6)[\text { current-smoking }] \\
1.6(1.2,2.1)[\text { past-smoking }]\end{array}$ & questionnaire & case-control & physician & current \\
\hline Briggs 2014 & 1012 & 576 & $1.27(1.03,1.58)[$ ever-smoking] & $\begin{array}{c}\text { telephone } \\
\text { questionnaire }\end{array}$ & case-control & McDonald & before onset \\
\hline Asadollahi 2013 & 662 & 394 & $1.78(1.22,2.59)[$ ever-smoking] & $\begin{array}{c}\text { Face or telephone } \\
\text { interview }\end{array}$ & case-control & McDonald or Poser & before onset \\
\hline Hedström 2013 & 6990 & 8279 & $\begin{array}{l}1.49(1.40,1.59)[\text { ever-smoking] } \\
1.56(1.45,1.67)[\text { current-smoking] } \\
1.35(1.24,1.47)[\text { past-smoking] }\end{array}$ & questionnaire & case-control & McDonald & before onset \\
\hline $\begin{array}{c}\text { Ramagopalan } \\
2013\end{array}$ & 3157 & 756 & 1.32(1.10,1.60)[ ever-smoking] & questionnaire & case-control & N/A & current \\
\hline Kotzamani 2012 & 504 & 591 & $1.9(1.50,2.41)[$ ever-smoking $]$ & questionnaire & case-control & $\mathrm{N} / \mathrm{A}$ & before onset \\
\hline Al-Afasy 2010 & 101 & 202 & $1.7(0.9,2.4)[$ ever-smoking $]$ & face interview & case-control & neurologist & before onset \\
\hline Maghzi 2011 & 516 & 1090 & $2.67(1.70,4.21)[$ ever-smoking] & questionnaire & case-control & McDonald & before onset \\
\hline Alonso 2011 & 394 & 394 & $1.72(0.90,3.30)[$ ever-smoking] & telephone interview & case-control & McDonald & before onset \\
\hline Simon $2010 \mathrm{a}$ & 210 & 420 & $1.4(1.0,2.0)[$ ever-smoking] & questionnaire & case-control & $\mathrm{N} / \mathrm{A}$ & before onset \\
\hline Simon $2010 b$ & 136 & 272 & $1.5(1.0,2.4)[$ ever-smoking $]$ & interview & case-control & Poser & before onset \\
\hline
\end{tabular}




\begin{tabular}{|c|c|c|c|c|c|c|c|}
\hline Simon $2010 c$ & 96 & 173 & $1.4(0.8,2.4)[$ ever-smoking $]$ & questionnaire & case-control & N/A & before onset \\
\hline Carlens 2010 & 214 & 277777 & $\begin{array}{l}2.5(1.7,3.6)[\text { ever-smoking }] \\
2.8(1.9,4.2)[\text { current-smoking }] \\
1.6(0.9,2.8)[\text { past-smoking }]\end{array}$ & $\mathrm{N} / \mathrm{A}$ & cohort & $\mathrm{N} / \mathrm{A}$ & before onset \\
\hline Jafari 2009 & 136 & 204 & $\begin{array}{l}1.09(0.68,1.73)[\text { ever-smoking] } \\
1.03(0.61,1.73)[\text { current-smoking] } \\
1.19(0.65,2.20)[\text { past-smoking] }\end{array}$ & questionnaire & case-control & McDonald & before onset \\
\hline Silva 2009 & 81 & 81 & $2.0(0.9,4.3)[$ current-smoking] & face interview & case-control & Poser & current \\
\hline Russo 2008 & 94 & 53 & $1.83(0.86,3.87)[$ ever-smoking $]$ & $\mathrm{N} / \mathrm{A}$ & case-control & McDonald & N/A \\
\hline $\begin{array}{c}\text { Pekmezovic } \\
2006\end{array}$ & 196 & 210 & $1.6(1.08,2.37)[$ ever-smoking] & face interview & case-control & Poser & before onset \\
\hline Hernán 2005 & 210 & 1913 & $\begin{array}{l}1.3(1.0,1.7)[\text { ever-smoking }] \\
1.4(1.0,1.9)[\text { current-smoking }] \\
1.0(0.6,1.8)[\text { past-smoking }]\end{array}$ & questionnaire & case-control & Poser & before onset \\
\hline Riise 2003 & 87 & 22312 & $1.81(1.13,2.92)[$ ever-smoking] & questionnaire & cohort & Self-report & before onset \\
\hline Zorzon 2003 & 140 & 131 & $1.50(0.90,2.40)[$ ever-smoking] & Interview & case-control & McDonald & before onset \\
\hline Hernán 2001 & 314 & 238371 & $\begin{array}{l}1.6(1.2,2.1)[\text { current-smoking] } \\
1.2(0.9,1.6)[\text { past-smoking] }\end{array}$ & questionnaire & cohort & physician & before onset \\
\hline Ghadirian 2001 & 200 & 202 & $1.6(1.0,2.4)[$ ever-smoking $]$ & face interview & case-control & N/A & before onset \\
\hline Thorogood 1998 & 114 & 46000 & $1.2(0.8,1.8)[1-14 \backslash \mathrm{day}]$ & N/A & cohort & physician & before onset \\
\hline Villard 1993 & 63 & 17032 & $1.5(0.6,3.3)[$ ever-smoking $]$ & $\mathrm{N} / \mathrm{A}$ & cohort & N/A & before onset \\
\hline
\end{tabular}


Table 2 (on next page)

Odds ratio and $95 \%$ confidence intervals for different subgroups of studies. 
1

\begin{tabular}{ccccc}
\hline Subgroups & $\begin{array}{c}\text { Number of } \\
\text { studies }\end{array}$ & Odds ratio & $95 \%$ CIs & $\begin{array}{c}\text { p-value for } \\
\text { comparison }\end{array}$ \\
\hline Case-control & 24 & 1.56 & $1.49-1.63$ & 0.362 \\
Cohort & 5 & 1.70 & $1.42-2.03$ & \\
McDonald/ Poser criteria & 16 & 1.70 & $1.52-1.90$ & 0.124 \\
Physician/self-reported/not reported & 13 & 1.52 & $1.39-1.66$ & \\
Adjustment for covariates & 15 & 1.51 & $1.43-1.59$ & 0.005 \\
No adjustment & 14 & 1.74 & $1.60-1.89$ & \\
Self-administrated questionnaire & 14 & 1.58 & $1.43-1.74$ & 0.674 \\
Face or telephone interview/not report & 15 & 1.63 & $1.47-1.82$ & \\
\hline
\end{tabular}

2 